\title{
Paternal uniparental disomy of chromosome 5
}

INSERM

\section{Source}

INSERM. (1999). Orphanet: an online rare disease and orphan drug data base. Paternal uniparental disomy of chromosome 5. ORPHA:96190

Paternal uniparental disomy of chromosome 5 is an uniparental disomy of paternal orig in that most likely does not have any phenotypic expression except from cases of homozygosity for a recessive disease mutation for which only father is a carrier. 